\title{
Educação física, ciência e saúde: notas sobre o acervo do Centro de Memória do Esporte (UFRGS)
}

\author{
Physical education, science, and health: notes on the holdings \\ of the Center for Sports Memory (UFRGS)
}

\author{
Silvana Vilodre Goellner \\ Professora da Escola de \\ Educação Física e do Programa \\ de Pós-graduação em Ciências do \\ Movimento Humano; coordenadora \\ do Centro de Memória do Esporte/ \\ Universidade Federal do Rio Grande \\ do Sul \\ Escola de Educação Física da UFRGS \\ Rua Felizardo, 750 \\ 90690-200 - Porto Alegre - RS - \\ Brasil \\ goellner@terra.com.br
}

GOELLNER, Silvana Vilodre. Educação física, ciência e saúde: notas sobre o acervo do Centro de Memória do Esporte. História, Ciências, Saúde - Manguinhos, Rio de Janeiro, v.17, n.2, abr.-jun. 2010, p.527-536.

\section{Resumo}

Apresenta breve inventário do acervo do Centro de Memória do Esporte e de suas principais coleções. Destaca sua relevância para as pesquisas sobre a historiografia das práticas corporais e esportivas e sua aproximação com a saúde, a educação e o lazer. Situa a estruturação da educação física brasileira no início do século XX e a importância que o conhecimento científico teve nesse período, sobretudo pela articulação desse campo de conhecimento com a eugenia e o higienismo. Nessa relação, as atividades físicas foram identificadas como integrantes de um projeto nacional cujos desdobramentos se fizeram sentir em diferentes níveis de atuação, fazendo ver que a educação física somente se faria consistente se ancorada no saber científico, prevalentemente biomédico.

Palavras-chave: educação física; ciência; saúde; Brasil.

\section{Abstract}

The article offers a brief inventory of the holdings of the Center for Sports Memory and its main collections. It underscores their relevance to research on the historiography of body and sporting practices and their relation to health, education, and leisure. The structuring of physical education in Brazil dates to the early twentieth century, a time when scientific knowledge was important, especially in terms of the ties between this field and eugenics and hygienism. Physical activities were identified as part of a national project that could be felt at various levels and that made it evident that physical education would only display consistency if anchored in scientific knowledge, primarily biomedical.

Keywords: physical education; science; health; Brazil 


\section{Educação física: historicidades inscritas nos corpos}

A aproximação entre educação física, ciência e saúde não é recente. Desde meados do século XIX constata-se a importância das atividades físicas como forma de potencializar a saúde dos brasileiros e das brasileiras, nos discursos da elite política e cultural do país. Tal necessidade era indicada para o fortalecimento da raça, pois a constituição homogênea do povo brasileiro passou a ser o pilar fundamental de um projeto de humanidade centrado na eliminação de tudo aquilo corporalmente intolerável. A crença na transformação da sociedade por meio da educação do corpo adquiriu contornos mais sofisticados com a recorrência aos preceitos da higiene e da eugenia, identificados como saberes científicos necessários para a consolidação desse intento.

No Brasil do início do século XX não havia escolas de formação de educadores físicos, e o saber dos professores geralmente se limitava à instrução prática. As atividades físicas, ainda que reconhecidas no plano educacional, praticamente inexistiam nas instituições de ensino. Elas passaram a se popularizar a partir da intervenção dos médicos higienistas (Soares, 1994), que, sabedores da importância da educação do corpo, se encarregaram de divulgá-la ao conjunto da população. Em nome da saúde, os médicos interferiram no espaço privado das famílias e na intimidade dos indivíduos orientando a conduta de mulheres e homens sobre asseio, banhos, vestimentas, hábitos alimentares, relações afetivas e sexuais e prática de atividades físicas. Foi, portanto, com suas intervenções que a educação física nutriu-se de um saber científico que, gradativamente, se fez soberano e conferiu maior respeitabilidade à pratica da ginástica e dos esportes, a qual, uma vez prescrita pelo médico, deveria ser orientada tanto por militares quanto por professores e instrutores.

Ainda que a melhoria saúde da população brasileira fosse uma preocupação desse tempo, a ação dos higienistas não se direcionava unicamente para isso. Estava atrelada a um projeto político de abrangência nacional, que apresentava como um dos principais objetivos fortalecer a 'raça' (Silva, 2004). Imersa nesse cenário, a educação física legitimouse como importante espaço de educação do corpo, entendida como o desenvolvimento das potencialidades orgânicas dos indivíduos e das virtudes da raça.

A concretização de tamanho objetivo demandava conhecimentos advindos da área da educação física, que, ao articular-se com a medicina e as normas jurídicas, atuaria em favor da ordenação de corpos ágeis, fortes e saudáveis. Não é sem razão que corresponde aos anos 1930 e 1940 a implementação, por parte do Estado, de ações direcionadas para a estruturação dessa área específica, com a criação do Ministério dos Negócios da Educação e Saúde Pública (1931); a transformação do Centro Militar de Educação Física - criado em 1922 - na Escola de Educação Física do Exército (1933); a criação da Divisão de Educação Física do Departamento Nacional de Educação (1937); a referência explícita à educação física na Constituição de 1937, outorgada por Getulio Vargas; a instalação da Comissão Nacional de Desportos; a criação da Escola Nacional de Educação Física e Desportos da Universidade do Brasil (1939); e a adoção oficial do Método Ginástico Francês (1931) como o método a ser trabalhado nas aulas de educação física das escolas brasileiras.

A edificação de uma educação voltada para o fortalecimento da nação tinha como proposta a unificação nacional e a homogeneização de corpos. Acreditava-se que formar 
um cidadão ciente de seus deveres para com a pátria exigia uma tarefa intensa, minuciosa e com demasiada abrangência, afinal "o Brasil, como uma vasta área territorial, precisa de filhos fortes e sadios para sua prosperidade e grandeza de seus empreendimentos nacionais" (Castro, 1933, p.13). A educação do corpo, materializada na educação física, configurou-se então como uma possibilidade de intervenção em prol desse fortalecimento, o que de certo modo explica o caráter higiênico, eugênico e disciplinador que lhe foi imputado no período. Ao valorizar a ordem e a disciplina, a exercitação física poderia proporcionar, além do desenvolvimento harmônico do corpo, o robustecimento do caráter, formando homens física e moralmente sadios, cientes de suas responsabilidades para com a pátria e habilitando as mulheres para uma missão não menos importante: a preparação de seu corpo e espírito para conduzir uma maternidade sadia e, assim, gerar bons frutos à nação.

Ao buscar modelar os corpos físicos, a eugenia seria a ciência a remodelar o corpo social pelo revigoramento orgânico e pela instauração de uma consciência cívica no cidadão, ao passo que a higiene asseguraria aos homens e mulheres uma condição física e moral capaz de garantir robustez e integridade às gerações futuras, aumentando o 'capital-saúde' da população.

Argumentos ancorados no fortalecimento do corpo e do comportamento legitimaram, também, a inserção das atividades físicas no contexto da educação escolarizada, visto que sua prática sistemática era percebida como algo a proporcionar benefícios a crianças e jovens, em especial os mais fracos. A ideia de fraqueza não se relacionava somente a questões orgânicas, mas também, e principalmente, à carência de atributos morais, que levavam a população à indolência e ao desânimo. Supunha-se que tal estado orgânico só se mantinha porque os sujeitos não haviam desenvolvido suficientemente atributos como virilidade, hombridade e coragem, considerados fundamentais para a ideia da constituição do corponação: um corpo que representasse o brasileiro liberto e moderno (Goellner, Fraga, 2004).

Legar robustez e integridade às gerações futuras passou integrar o conjunto de objetivos da política nacional de desenvolvimento do país (Marques, 1994). O propósito encontrou apoio em categorias profissionais como médicos, intelectuais, militares, dirigentes políticos e professores, que não pouparam esforços para consolidá-lo (Schwarcz, 1993). Entre as várias ações desenvolvidas em prol desse aprimoramento, destaca-se o amplo incentivo conferido à prática de atividades físicas, percebidas como fundamentais para o fortalecimento da saúde dos indivíduos e do próprio país.

Fernando de Azevedo, importante intelectual da época, defendia a incorporação da educação física nos projetos que buscavam a regeneração nacional. Acreditava que os saberes próprios desse campo de conhecimento iriam fortalecer o corpo do cidadão, a fim de despertar nele qualidades inatas antes adormecidas: "Uma vez introduzida pela educação nos hábitos do país, a prática d'esta cultura física, sustentada durante uma larga série de gerações, depuraria a nossa raça de diáteses mórbidas, locupletando-a, progressivamente pela criação incessante de indivíduos robustos" (Azevedo, 1919, p.229).

A articulação entre saberes pedagógicos e médicos sustentou a estruturação da educação física brasileira e, de outros modos, ainda a sustenta na atualidade. No início do século $\mathrm{XX}$, com base em preceitos higiênicos e eugênicos, incentivavam-se as atividades físicas objetivando a melhoria das capacidades orgânicas dos indivíduos. Hoje, outras são as 
representações ligadas a essas práticas. Aptidão física, performance, qualidade de vida, estética, boa forma, vida saudável são exemplos de expressões frequentes em diversos discursos que circulam em distintos espaços sociais. Apreender suas nuanças implica compreender a historicidade dessas práticas. Significa, ainda, perceber as articulações que, em diferentes momentos históricos, foram (e são) estabelecidas entre exercitação física, saúde, educação e lazer. Daí a importância de museus esportivos e centros de documentação cujos acervos abrigam fontes que, uma vez investigadas, podem 'dizer' dessas relações e dos saberes e práticas que as materializam no cotidiano dos sujeitos.

Recorrer, portanto, à memória e à história para melhor conhecer as relações entre educação física, ciência e saúde significa recorrer a textos, imagens, sons, objetos, monumentos, equipamentos, vestes, depoimentos orais e tantas outras produções humanas, entendendo-as como possibilidade de compreender que ali estão inscritas sensações, representações, valores, mensagens e preconceitos que permitem conhecer parte do tempo em que foram produzidas. Significa, também, recuperar do esquecimento alguns vestígios e testemunhos que podem revelar um tempo que pouco conhecemos: o tempo em que se estruturaram as práticas corporais e esportivas da sociedade onde vivemos.

\section{O Centro de Memória do Esporte como um lugar da memória'}

O Centro de Memória do Esporte (Ceme $)^{2}$ foi implantado na Escola de Educação Física da Universidade Federal do Rio Grande do Sul (UFRGS) em dezembro de 1996. Desde então tem atuado como local de recuperação e preservação de fontes documentais escritas, orais e iconográficas relacionadas à educação física e às práticas corporais e esportivas. Para além da guarda e preservação de acervos, desenvolve uma política que busca divulgá-los junto a diferentes públicos e interesses, por meio de incentivo a pesquisas e de seu desenvolvimento, publicação de livros, realização de exposições, mostras fotográficas e oficinas pedagógicas, organização de acervo oral, digitalização de fotografias e documentos e disponibilização de fontes através de recursos computacionais, entre outros.

Voltado para a preservação da memória histórica e para a produção de conhecimentos, seu acervo traz contribuições importantes para a história da saúde no Brasil. Afinal, não se pode pensar em saúde sem tomar como referência o corpo, dado que nossa própria existência é corporal (Le Breton, 2006). Com base nas fontes que o Ceme abriga e produz, é possível identificar diferentes representações de saúde e sua associação com a atividade física, bem como visualizar como, desde o século XIX, se construiu um minucioso processo de educação do corpo, de educação da gestualidade, dos modos de ser, parecer, sentir e agir de brasileiros e brasileiras. Colabora para que se possa apreender como cada tempo e cultura elaborou e elabora uma espécie de retórica corporal, isto é, os cuidados com o corpo, as relações entre saúde e doença, as formas de se movimentar e expressar, os adornos corporais, o asseio, a alimentação, as práticas sexuais, os gestos e seus significados - enfim, todas as formas que marcam os funcionamentos do corpo.

Atualmente seu acervo é composto por mais de três mil livros, publicados antes de 1960, e mais de dez mil documentos textuais (atas, jornais, correspondências, diários, cadernos de chamada, programas de cursos, fichas de avaliação funcional, prescrições de exercícios 
etc). Reúne inúmeras obras como manuais médicos, atlas de anatomia e livros sobre educação física, saúde, higiene, eugenia, ginástica e esporte, editados desde o século XIX nos idiomas inglês, espanhol, alemão, francês, italiano e sueco. Possui, ainda, mais de três mil fotografias e cerca de dois mil artefatos como medalhas, troféus, vestuário, aparelhos antropométricos e flâmulas. Está estruturado nas seguintes coleções:

- Educação Física, com mais de cinco mil documentos textuais, datados a partir do século XIX, com destaque para o acervo de Jacinto Targa, um dos fundadores da Escola de Educação Física da UFRGS, profissional reconhecido no Brasil e exterior;

- Olímpica, composta por materiais relacionados aos esportes olímpicos desde a primeira edição dos Jogos Olímpicos Modernos, em 1896;

- Dança, que reúne documentação referente a essa arte no Brasil e no exterior, além de farto material sobre os primórdios da dança no Rio Grande do Sul. Parte dessa coleção foi obtida em 1998, com a aquisição do acervo de João Luiz Rolla, um dos primeiros professores de dança no Estado;

- Lazer e Recreação Pública, que reúne material relativo ao desenvolvimento desse campo no Brasil, desde sua estruturação;

- Universíade 63, com documentos, fotos e artefatos relacionados aos Jogos Mundiais Universitários, ocorridos em Porto Alegre em 1963. Organizados pela Federação Internacional do Esporte Universitário (Fisu), a edição em Porto Alegre foi a primeira a acontecer fora do contexto europeu;

- Colégio Brasileiro de Ciência do Esporte: constitui o acervo histórico dessa entidade, considerada a maior na área de educação física, que foi transferido para o Ceme em 2003;

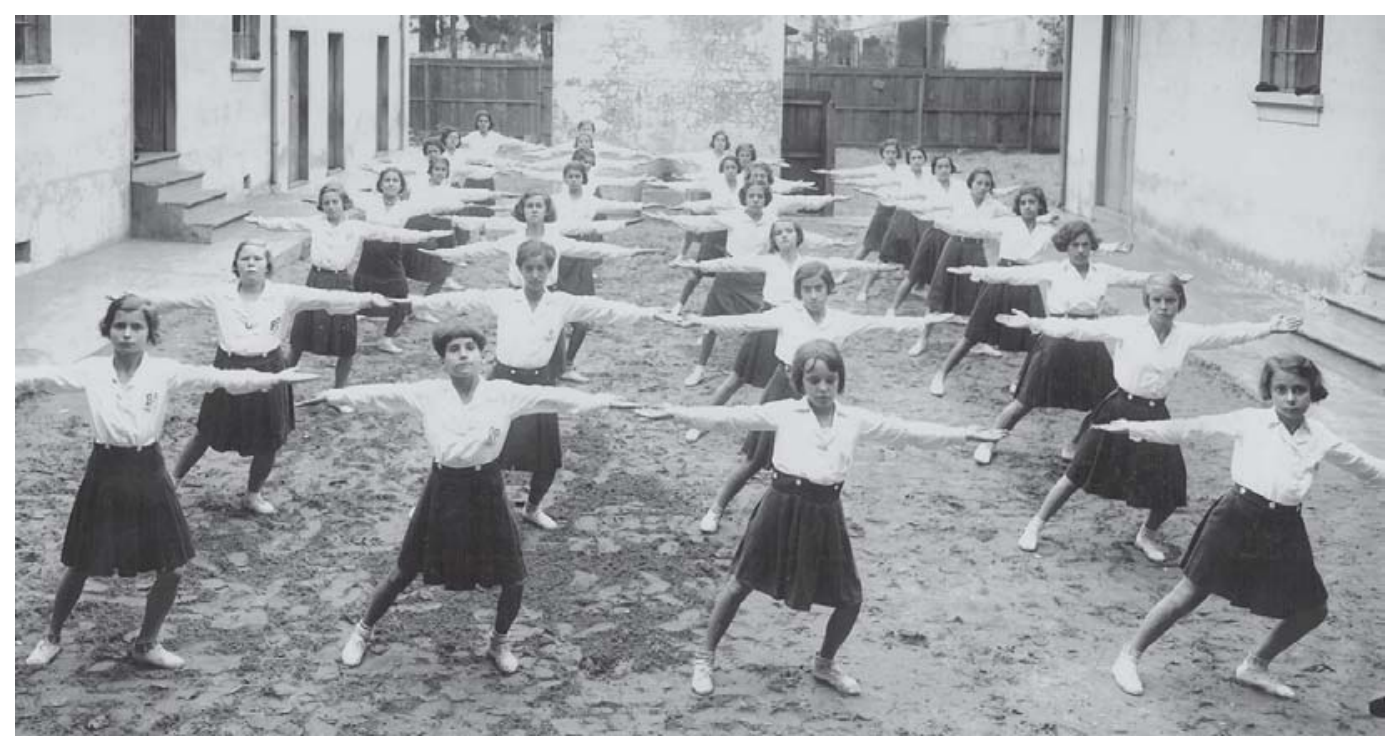

Figura 1: Ginástica para meninas; aula de educação física escolar em Porto Alegre, na década de 1930. (Acervo Ceme) 


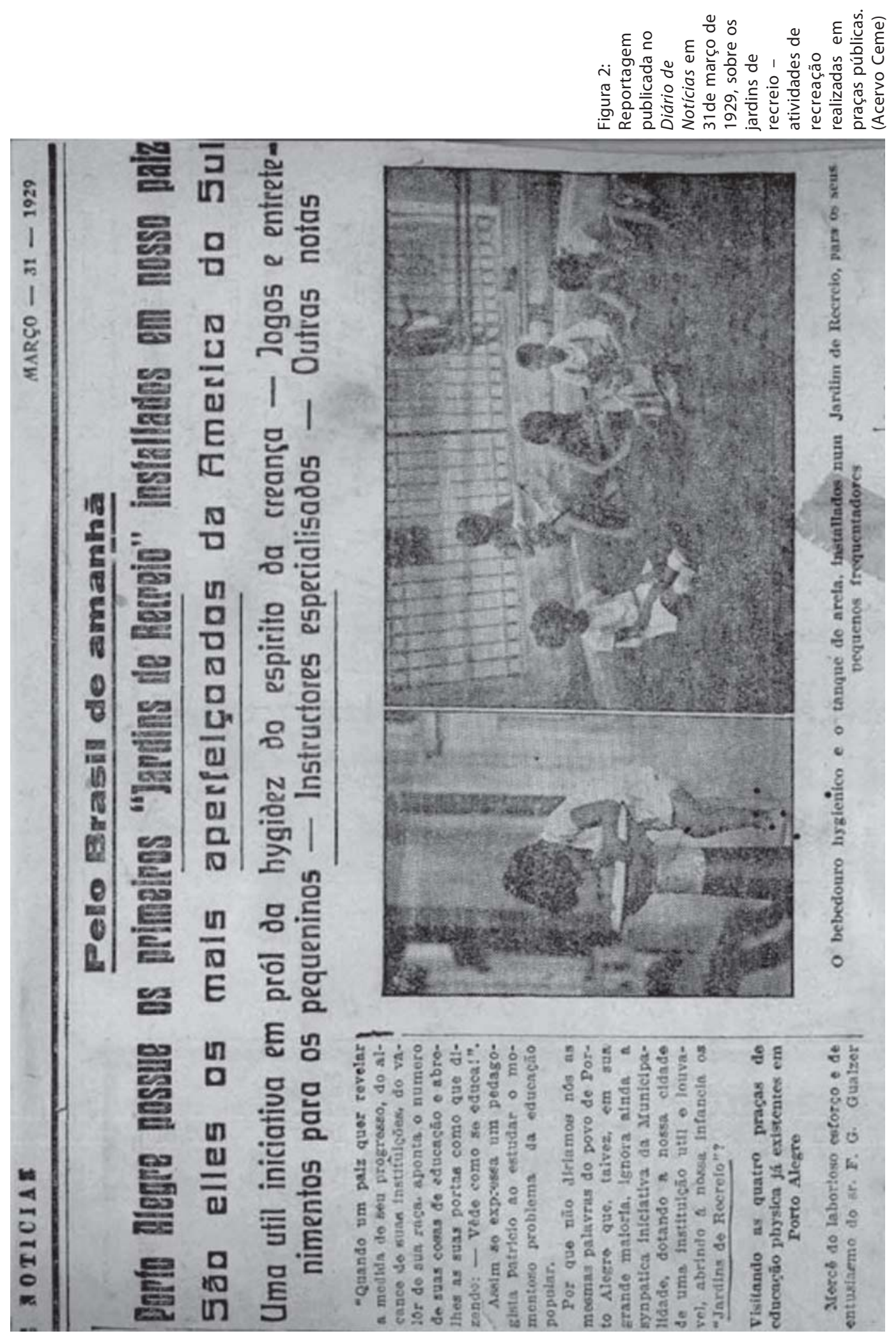


Entre as inúmeras fontes documentais que o acervo preserva, destacam-se obras inaugurais de autores brasileiros a escrever sobre a educação física, bem como traduções de livros e periódicos que fundamentaram a estruturação desse campo acadêmico no Brasil, tais como: Da educação física: o que ela é, o que tem sido e o que deveria ser (1920) e Antinoüs: estudo de cultura atlética (1919), de Fernando de Azevedo, esta última uma edição da conferência pronunciada na fundação da Sociedade Eugênica de São Paulo; Educação fisica feminina (1930), primeira obra escrita no Brasil sobre o tema, cujo autor, Orlando Rangel Sobrinho, era tenente do Exército brasileiro; Regulamento de educação física (1930), tradução do Règlement general d'éducation physique, produzido pela Escola Militar de JoinvilllelePont, na França, em 1927 e adotado, no Brasil, como o método oficial do ensino da educação física nos anos 1930 e 1940; grande parte das obras sobre educação física publicadas por Inezil Penna Marinho3; estudos pioneiros de Fredrico Guilherme Gaelzer ${ }^{4}$ e vasta documentação sobre a institucionalização do lazer e da recreação pública no Brasil; Melhoremos e prolonguemos a vida: a valorização eugênica do homem (1922) e Porque sou higienista: 20 anos de campanha eugênica, 1917-1937 (1937), de Renato Kehl; Ginástica de quarto: higiênica e terapêutica, publicada em 1887 por Daniel Gottlieb Schreber, ortopedista alemão que via na ginástica uma forma de corrigir defeitos anatômicos; as coleções completas dos primeiros periódicos específicos sobre educação física editados no Brasil, Educação Física: Revista de Esportes e Saúde, publicada por professores civis entre 1932 e 1945, e Revista Brasileira de Educação Física, editada pelo Exército, cujo primeiro número circulou em outubro de 1932. Possui, ainda, edições de aproximadamente oitenta periódicos nacionais e internacionais que tematizam educação física, esporte, ciências do esporte e medicina esportiva.

Listar o acervo do Centro de Memória é tarefa demasiado grande e pouco produtiva. Mais relevante do que explicitar todos os registros históricos sob a guarda do Ceme é

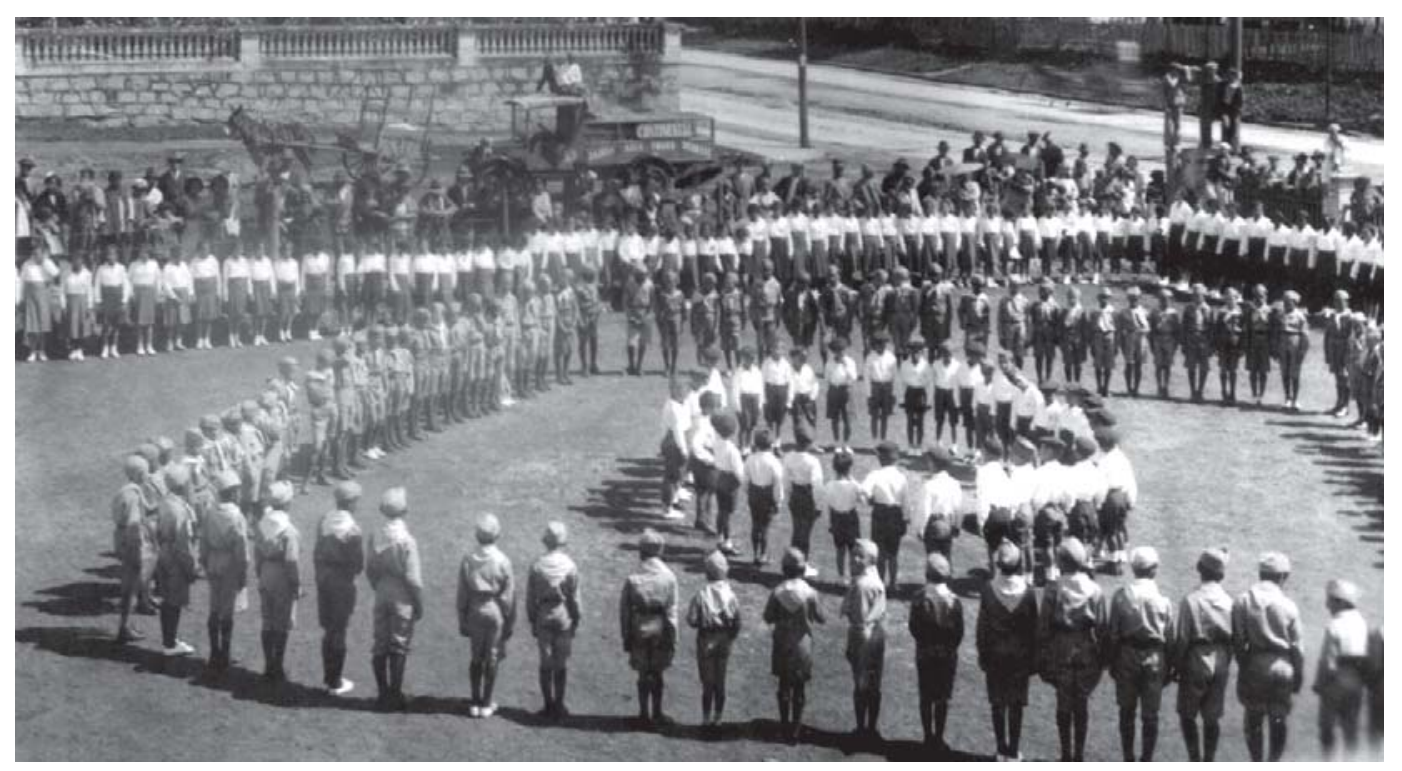

Figura 3: Comemorações da Semana da Raça, Porto Alegre, 1932. (Acervo Ceme) 


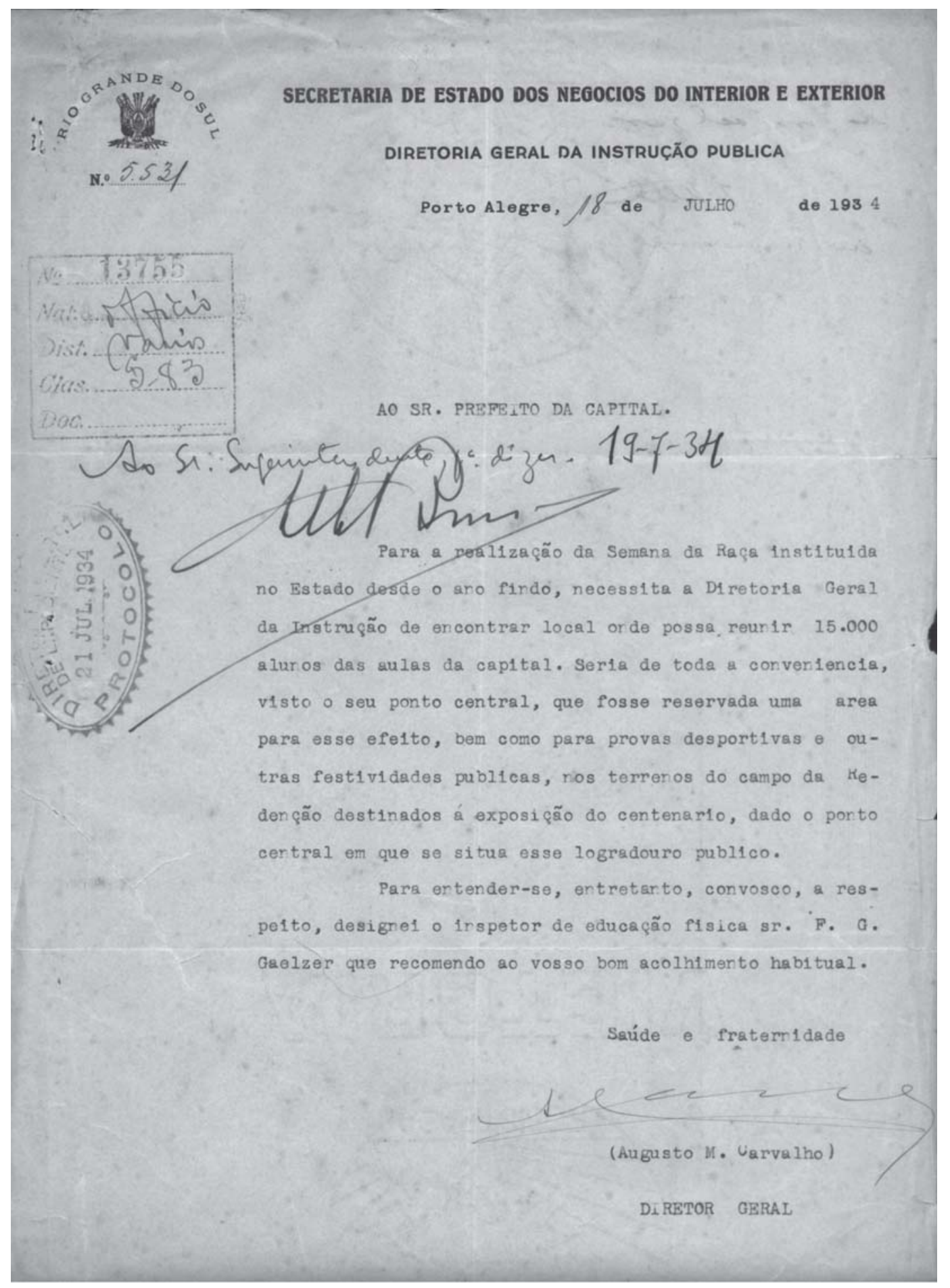

Figura 4: Oficio do diretor-geral da Instrução Pública para o prefeito de Porto Alegre, sobre a organização da Semana da Raça. Porto Alegre, 1934. (Acervo Ceme) 
evidenciar que suas coleções permitem compreender que a constituição da denominada área de educação física, no Brasil, se deu com a articulação entre os pensamentos médicohigienista, militar e pedagógico. Na interface dessas intervenções, gradativamente as práticas corporais e esportivas foram identificadas como integrantes de um projeto nacional, cujos desdobramentos se fizeram sentir em diferentes níveis de atuação: na elaboração de políticas públicas para a área; na criação de periódicos específicos; na elaboração de leis, decretos e resoluções oficializando a ginástica como conteúdo obrigatório da educação escolarizada; na composição de fichas antropométricas objetivando a classificação de escolares e, a partir delas, na elaboração de programas de atividades físicas visando melhorias em sua saúde; na criação de programas de recreação e lazer destinados à população em geral; na publicação de obras bibliográficas; enfim, uma sorte de produções a atestar que a educação física brasileira somente se faria consistente se ancorada no saber científico, prevalentemente biomédico.

Entendendo que as práticas corporais e esportivas são constitutivas não apenas da vida cotidiana de um país, mas também de referências identitárias de sua cultura e população, acervos como o do Centro de Memória do Esporte são relevantes para a compreensão da historicidade das práticas corporais, da educação, do lazer e da saúde. Como lugares da memória, não são apenas espaços onde se depositam velhas imagens, ideias, objetos e palavras. Ao contrário, neles se reúnem vivas experiências que ajudam a entender o presente não no sentido de justificá-lo, mas sim com o intuito de buscar respostas aos inúmeros questionamentos que hoje podemos empreender. Afinal, a memória não nos aprisiona ao passado, mas nos conduz a indagar o presente, a indagar sobre o mundo, os outros e nós mesmos.

\section{NOTAS}

${ }^{1}$ Expressão criada pelo historiador Pierre Nora (1984), para quem os lugares da memória assim o são em uma tríplice acepção: são lugares materiais, onde a memória social se ancora e pode ser apreendida pelos sentidos; são lugares funcionais, porque têm ou adquiriram a função de alicerçar memórias coletivas; e são lugares simbólicos, onde essa memória coletiva - vale dizer, essa identidade - se expressa e revela. São, portanto, lugares carregados de uma vontade de memória.

${ }^{2}$ O Centro de Memória do Esporte (Ceme) situa-se na cidade de Porto Alegre, no Rio Grande do Sul. Seu acervo documental e iconográfico encontra-se em processo de digitalização desde o final de 2007. Parte dele está disponível para consulta na sua página na Internet (http://www6.ufrgs.br/esef/ceme/index.html). Os documentos também podem ser consultados in loco. Mais informações podem ser obtidas no site do Ceme.

${ }^{3}$ Instrutor de educação física pela Escola de Educação Física do Exército e técnico desportivo pela Escola Nacional de Educação Física e Desportos da Universidade do Brasil. Tinha formação, ainda, em ciências jurídicas e sociais, psicologia e filosofia. Ocupou o cargo de técnico em educação no Ministério da Educação entre 1940 e 1971. Escreveu mais de cem livros tecendo diálogos fecundos entre a educação física e as seguintes áreas de conhecimento: direito e legislação, filosofia, folclore, história, pedagogia, psicologia e sociologia.

${ }^{4}$ Na década de 1920 Gaelzer estagiou na Associação Cristã de Moços, nos Estados Unidos, e com base nessa experiência elaborou para o Brasil programas de lazer como colônias de férias e recreação em parques e praças. Nesses programas observa-se uma relação bastante próxima entre saúde e lazer, pois através do desenvolvimento de atividades físicas nos espaços públicos da cidade buscava-se melhorar as condições de saúde da população, revigorando suas forças. As colônias de férias eram propostas sob supervisão dos médicos, a quem cabia prescrever as atividades que, além de lúdicas, envolviam preceitos da educação higiênica como cuidados com a limpeza corporal e exposição ao sol. 


\section{REFERÊNCIAS}

AZEVEDO, Fernando de.

Da educação physica: o que ela é, o que tem sido e o que deveria ser. São Paulo: Weiszflog Irmãos. 1920.

AZEVEDO, Fernando de.

Antinoüs: estudo de cultura atlhetica.

São Paulo: Weiszflog Irmãos. 1919.

BRASIL.

Estado Maior do Exército. Regulamento de educação física. Rio de Janeiro: Biblioteca A Defesa Nacional. 1930.

CASTRO, Leite de.

O método francês na Polícia Especial. Revista Educação Física, Rio de Janeiro, n.9, p.12-14. 1933.

GOELLNER, Silvana Vilodre; FRAGA, Alex Branco.

A inominável Sandwina e as obreiras da vida: silêncios e incentivos nas obras inaugurais de Fernando de Azevedo. Revista Brasileira de Ciências do Esporte, São Paulo, v.26, n.1. p.71-84. 2004.

KEHL, Renato.

Porque sou higienista: 20 anos de campanha augência, 1917-1937. Rio de Janeiro: Livraria Francisco Alves. 1937.

KEHL, Renato.

Melhoremos e prolonguemos a vida: a valorização eugênica do homem, 1917-1937. Rio de Janeiro: Livraria Francisco Alves. 1922.
LE BRETON, David.

A sociologia do corpo. Petrópolis: Vozes. 2006.

MARQUES, Vera Regina Beltrão.

A medicalização da raça: médicos, educadores e discurso eugênico. Campinas: Unicamp. 1994.

NORA, Pierre.

Entre memóire et histoire: la problématique des lieux. In: Nora, Pierre (Org). Les lieux de mémoire. Paris: Gallimard. p.VII-XLII. 1984.

RANGEL SOBRINHO, Orlando.

Educação physica feminina. Rio de Janeiro: Typografica do Patronato. 1930.

SCHREBER, Daniel Gottlieb Morritz.

Gymnastica de quarto: hygienica e therapeutica. Rio de Janeiro: Typografia da Gazeta de Noticias. 1887.

SCHWARCZ, Lilia Moritz.

O espetáculo das raças: cientistas, instituições e a questão racial no Brasil. São Paulo: Companhia das Letras. 1993.

SILVA, Maria Cecília.

A educação física escolar/saúde: o discurso médico no século XIX. Revista Brasileira de Ciências do Esporte, São Paulo, v.26, n.1. p.97-112. 2004.

SOARES, Carmen.

Educação física: raízes históricas e Brasil. Campinas: Autores Associados. 1994. 